\title{
Bibliometric study of articles published in a Brazilian journal of pediatric dentistry
}

\section{Vanessa Ceolin Poletto(a) Italo Medeiros Faraco Junior ${ }^{(b)}$}

(a) Graduate Student in Pediatric Dentistry; (b)PhD, Department of Pediatric Dentistry - Lutheran University of Brazil, Canoas, RS, Brazil.
Corresponding author:

Vanessa Ceolin Poletto

Rua Conde de Porto Alegre, 550 / 1402

- Bairro Floresta

Porto Alegre - RS - Brazil

CEP: 90220-210

E-mail:vpoletto@terra.com.br

Received for publication on Sep 09, 2009 Accepted for publication on Dec 01, 2009
Abstract: This cross-sectional study aimed at evaluating the abstracts of all articles published in the "Jornal Brasileiro de Odontopediatria e Odontologia do Bebê" in order to collect data on the study design used, the most researched topics and the Brazilian states with the highest scientific production. Copies were made of the abstracts of each article, totaling 572 abstracts. Data categorization was done by two trained and independent reviewers. The results showed that the most used study design were case report $(33 \%)$ and cross-sectional study $(30 \%)$. On the other hand, there were only $2.5 \%$ of randomized clinical trials and no systematic review or meta-analysis. The most researched topics were cariology $(15 \%)$ and restorative dentistry / dental materials $(10 \%)$. The state with the greatest number of publications was São Paulo (40\%), followed by Rio de Janeiro (17\%). It was concluded that the majority of the articles published referred to studies with a low potential to establish scientific evidence, indicating a need for conducting research based on better quality methodology. Moreover, it was found that the assessed literature reflected the trends observed in the clinical practice of Pediatric Dentistry in Brazil.

Descriptors: Bibliometrics; Dental research; Pediatric dentistry.

\section{Introduction}

Pediatric dentistry was defined several years ago as an age-defined specialty that comprises all dentistry aspects. ${ }^{1}$ It has also been described as a specialty that, above all, provides preventive and global therapeutic dental care for children and adolescents, including those who require special care, comprising a wide range of activities. ${ }^{2,3}$ Therefore, pediatric dentistry is becoming more and more committed to offer patients the latest scientific advancements in health care by seeking useful and consistent information in the medical literature to guide clinical conducts.

Health care professionals usually base their decisions on professional experience, prevailing clinical practice, standard procedures, training or expert guidance, peer consultation and knowledge acquired in dental school, seminars and continuing education programs. Clinical experience, technical expertise and critical judgment are essential but not sufficient. Due to the complexity of information, scientific support to clinical practice must be sought in the medical literature and derived from methodologically validated tools. ${ }^{4-6}$

Therefore, it is essential that studies be published, for they provide 
scientific basis to professionals in their search for better quality of life standards for the population.

Hence the importance of bibliometrics, which is being increasingly used in analyses of scientific production, and has become a statistical support device that allows mapping and generating different information and knowledge handling and management indicators, particularly in scientific, technological and productivity-related information and communication systems necessary to the planning, evaluation and management of a given scientific community or country. It is also a quantitative instrument that allows minimization of the subjectivity inherent to information indexation and retrieval, which produces knowledge in a given field. ${ }^{7-10}$

Since some studies suggest that dental publications present questionable results and evaluations, several bibliometric studies have been conducted to identify and quantify the available publications, as well as to assess the validity of the evidence based Dentistry considering type, quality and availability of these publications. ${ }^{7,10-14}$

Based on the considerations above, the present study evaluated all the articles published in the "Jornal Brasileiro de Odontopediatria e Odontologia do Bebê" (JBP), and assessed the study design used, the area of interest of the research and the Brazilian state where the research was conducted.

\section{Material and Methods Study design}

A cross-sectional study by direct observation of all the abstracts published in the "Jornal Brasileiro de Odontopediatria e Odontologia do Bebê" (19982007) was conducted.

\section{Data collection}

\section{Selection of articles and data extraction}

The abstract of each article was retrieved and copied, totaling 572 abstracts. They were separated by year and then subdivided into volume and issue number. Both the title and abstract were reviewed. Three items were evaluated for every abstract, as follows: study design, area of interest of the research and the Brazilian state where the research was conducted.
When it was not possible to characterize the three items of the research from the title and abstract alone, the whole article was retrieved and analyzed, so as to collect all the information necessary to complete the studied items. Data categorization was done by direct physical examination of the abstract of every reference, by two trained and independent reviewers. When there was disagreement in the evaluation of a given article, it was only classified when a consensus was reached among the reviewers.

The preface, editorials, letters to the editor and organization-related communications were excluded because they were not relevant to the scope of this study.

\section{Study design of the articles}

The study design described in the article was determined in every abstract. The study type was classified according to an adaptation of the classification proposed by Fletcher et al. ${ }^{15}$ (2005).

\section{Area of interest of the study}

With the purpose of evaluating the trends of the topics and subjects covered in the studies, each abstract was classified according to the topic covered by the corresponding article. Our scope was limited to 24 areas of interest according to an adaptation of the classification presented in the study by Nainar ${ }^{16}$ (2001).

\section{State of origin of the publication}

The Brazilian states where the study was conducted were identified according to the origin of the authors. Thus, the total number of publications in each state, as well as the scientific production of each state, was determined.

\section{Data analysis}

The instrument used to record the collected data consisted of a specific form with questions pertinent to the area of interest, type of study and Brazilian state of origin of the publication (Figure 1). These data were organized and analyzed using the software SPSS - version 13.0, and shown with the use of descriptive statistics. 
Figure 1 - Data collection form.

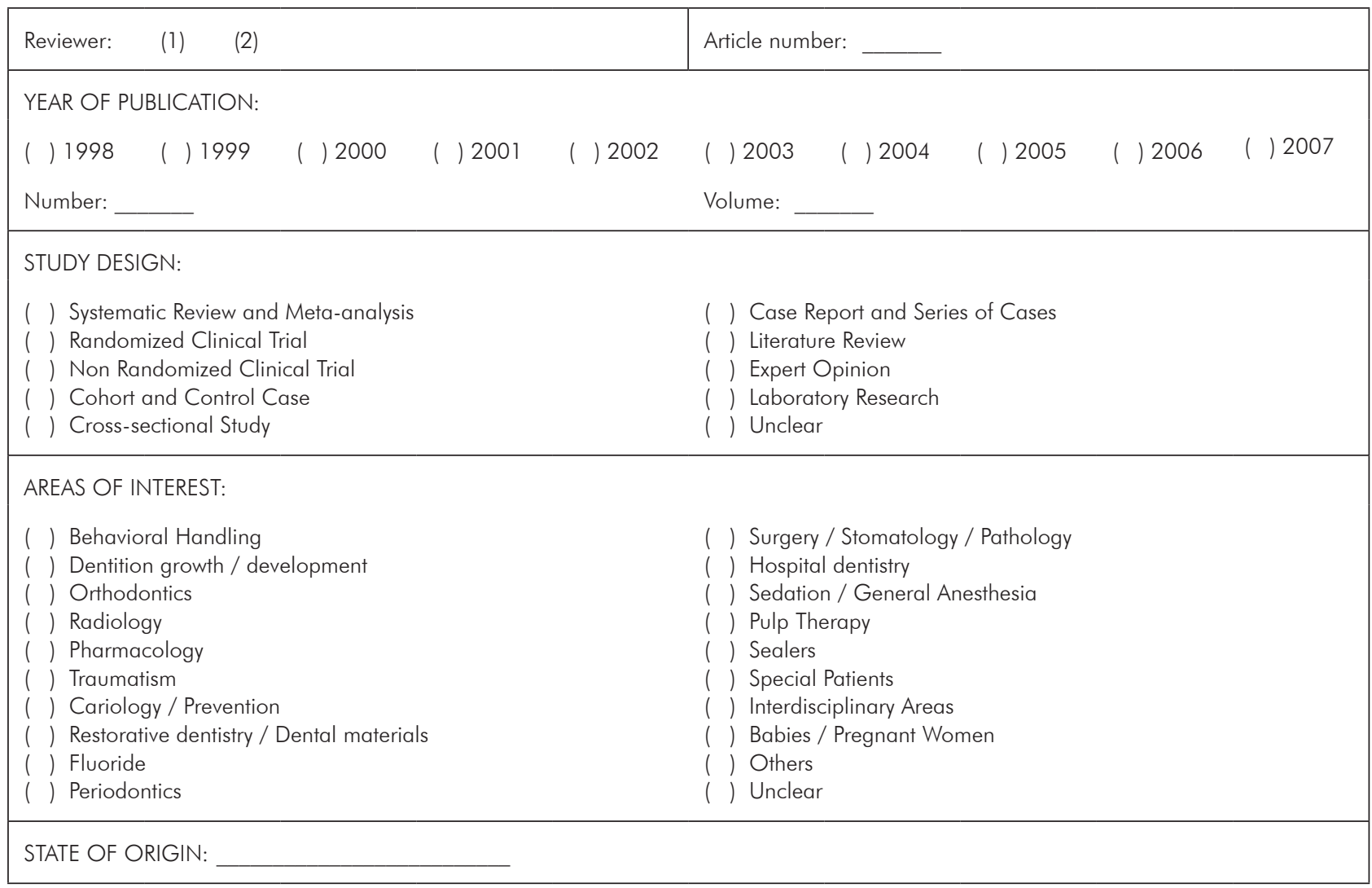

\section{Results}

Of the 572 articles analyzed, the most used study design was the case report, totaling 188 articles $(32.9 \%)$, and the cross-sectional study, with 170 articles $(29.7 \%)$. Only 14 articles $(2.4 \%)$ were randomized clinical trials. No examples of systematic review or meta-analysis were found (Table 1).

Table 2 shows the areas of interest of the scientific articles. Cariology was the most researched topic, represented by 120 (15.3\%) articles. The second most researched topic was restorative dentistry / dental materials and babies / pregnant women, with respectively $85(10.8 \%)$ and $81(10.3 \%)$ articles. On the other hand, there were only $3(0.4 \%)$ articles published on forensic odontology and laser.

Concerning the state with the greatest number of publications, it was found that São Paulo was responsible for $40.5 \%$ of the publications, followed by Rio de Janeiro with $16.8 \%$ and Minas Gerais with $7.5 \%$ (Table 3 ).
Table 1 - Frequency of study design types.

\begin{tabular}{l|c|c}
\hline \multicolumn{1}{c|}{ Study design } & (n) & $(\%)$ \\
\hline Case Report & 188 & 32.9 \\
\hline Cross-sectional study & 170 & 29.7 \\
\hline Literature Review & 129 & 22.6 \\
\hline Laboratory Research & 51 & 8.9 \\
\hline Randomized Clinical Trial & 14 & 2.4 \\
\hline Non Randomized Clinical Trial & 11 & 1.9 \\
\hline Expert Opinion & 8 & 1.4 \\
\hline Cohort and Case Control & 1 & 0.2 \\
\hline Systematic Review and Meta-Analysis & 0 & 0 \\
\hline Total & 572 & 100 \\
\hline
\end{tabular}

\section{Discussion}

The health sciences are undergoing great changes in the way they produce, use and interpret knowledge, so professionals must constantly try to keep abreast of the latest advances. A great deal of scien- 
Table 2 - Frequency of areas of interest.

\begin{tabular}{l|r|r}
\hline \multicolumn{1}{|c|}{ Areas of Interest } & (n) & (\%) \\
\hline Cariology / Prevention & 120 & 15.3 \\
\hline Restorative Dentistry / Dental materials & 85 & 10.8 \\
\hline Babies / Pregnant women & 81 & 10.3 \\
\hline Growth and development / anomalies / eruptions & 70 & 8.9 \\
\hline Special patients / syndromes & 70 & 8.9 \\
\hline Orthodontics / malocclusion / deleterious habits & 67 & 8.5 \\
\hline Surgery / stomatology / pathology & 51 & 6.5 \\
\hline Behavioral handling / psychology & 33 & 4.2 \\
\hline Dento-alveolar / facial trauma & 32 & 4.1 \\
\hline Interdisciplinary areas & 28 & 3.6 \\
\hline Pulp therapy & 25 & 3.2 \\
\hline Fluoride & 20 & 2.5 \\
\hline Periodontics & 20 & 2.5 \\
\hline Radiology / medical imaging & 18 & 2.3 \\
\hline Pharmacology / pain control / local anesthesia & 11 & 1.4 \\
\hline Others & 11 & 1.4 \\
\hline Health services and education & 9 & 1.2 \\
\hline Child abuse / ill treatment & 8 & 1.0 \\
\hline Sealers & 7 & 0.9 \\
\hline Sedation / general anesthesia / hospital dentistry & 5 & 0.6 \\
\hline Bruxism & 4 & 0.5 \\
\hline Adolescents & 3 & 0.5 \\
\hline Laser & 0.4 \\
\hline Forensic odontology & 3 & 0.4 \\
\hline Total & 70.0 \\
\hline
\end{tabular}

tific research has been made available, which helps disseminate the results obtained.

The valuing of clinical conducts based on evidence is no longer considered a matter of philosophy, but the result of the evolution of health sciences and, at the same time, of a decrease in the importance of ancient dogmas, ${ }^{17}$ because it is in the scientific literature that professionals seek relevant studies with methodological quality that provide the answers to their patients' requests.

The bibliometric assessment of the studies published in the "Jornal Brasileiro de Odontopediatria e Odontologia do Bebê" showed a predominance of case reports $(32.9 \%)$, a finding that agrees with the
Table 3 - Frequency of states.

\begin{tabular}{|c|c|c|}
\hline State & (n) & (\%) \\
\hline São Paulo & 231 & 40.5 \\
\hline Rio de Janeiro & 96 & 16.8 \\
\hline Minas Gerais & 43 & 7.5 \\
\hline Rio Grande do Sul & 39 & 6.8 \\
\hline Paraná & 29 & 5.1 \\
\hline Pernambuco & 24 & 4.2 \\
\hline Santa Catarina & 22 & 3.9 \\
\hline Paraíba & 15 & 2.6 \\
\hline Bahia & 12 & 2.1 \\
\hline Distrito Federal & 10 & 1.8 \\
\hline Mato Grosso do Sul & 9 & 1.6 \\
\hline Pará & 8 & 1.4 \\
\hline Goiás & 6 & 1.1 \\
\hline Espírito Santo & 4 & 0.7 \\
\hline Maranhão & 4 & 0.7 \\
\hline Mato Grosso & 4 & 0.7 \\
\hline Rio Grande do Norte & 4 & 0.7 \\
\hline Ceará & 3 & 0.5 \\
\hline Piauí & 3 & 0.5 \\
\hline Sergipe & 3 & 0.5 \\
\hline Alagoas & 1 & 0.2 \\
\hline Total & 572 & 100 \\
\hline
\end{tabular}

study conducted by Suehiro et al. ${ }^{14}$ (2007).

This study design is the most basic descriptive study. It is generally used in the initial evaluation of little known problems, with characteristics that are not well understood. Its main advantages are low cost and ease of performance, but its scope is limited because there is no control mechanism to attest to its efficiency, and because of the subjectivity involved in the appreciation of facts. ${ }^{5,15}$

Cross-sectional studies were found in $29.7 \%$ of the articles. No study of systematic review was found. Systematic reviews are strict reviews of specific clinical issues that summarize the original research, and meta-analysis, which consists on the combination of study findings, providing precise and concise estimates on a given topic. ${ }^{15}$ These data reflect the necessity to improve the quality of scientific 
papers, in accordance with the level of hierarchy of evidence-based dentistry. ${ }^{18}$

In a similar study, Luz et al. ${ }^{12}$ (2007) found that the most published designs were original research and literature review, with only one meta-analysis study.

In 2000 , Nainar ${ }^{17}$ found that $71 \%$ of the publications were descriptive studies and case reports. A percentage of $6 \%$ was found for articles of randomized and controlled clinical trials. According to the same study, the "Pediatric Dentistry" had more literature reviews and in vitro studies compared to the "Journal of Dentistry for Children".

On the other hand, Oliveira et al. ${ }^{13}$ (2007), in their evaluation of the design of the studies published from 1993 to 2003 in the "Journal of Brazilian Dentistry", found that $24 \%$ of the studies consisted of in vitro laboratory research, whereas in the present study laboratory research achieved only $8.9 \%$.

In the analysis of the areas of interest, there was a predominance of some topics in the journal evaluated by the present study, with cariology being the most researched area, representing $15.3 \%$ of the articles.

Nainar ${ }^{16}$ (2001) found a significant increase in the number of publications on cariology, including caries diagnosis, etiopathogeny and epidemiology in a study conducted from 1989 to 1998 . Most articles reviewed were on restorative dentistry and dental materials. The author noticed an increase in the number of publications on health services and pharmacological control research. Also, a decrease was found in the number of publications on behavior management, dental trauma, dentition growth and development, orthodontics and pulp therapy. In the present study, it was found that the areas of health services and education and behavioral handling totaled respectively $1.2 \%$ and $4.2 \%$.

The second most researched topic was restorative dentistry and dental materials, with a total $10.8 \%$ share. In a study by Yang et al. ${ }^{10}$ (2001), who conducted a bibliometric assessment of the pediatric dentistry literature in Medline, a significant increase in the publication of articles on restorative dentistry, with $9 \%$ of publications on this topic, was also confirmed.
Other areas that were found to be widely covered in the present research were related to babies and pregnant women, dentition growth and development, and special patients, showing new trends in research in the pediatric dentistry field.

The Brazilian scientific production has increased significantly in the past decades, ${ }^{19}$ and the State of São Paulo is the greatest responsible for this growth. Concerning the state of origin of the publications, the findings obtained showed that the State of São Paulo published $40.5 \%$ of the articles, corroborating the study by Cavalcanti et al. ${ }^{20}$ (2004) and Suehiro et al. ${ }^{14}$ (2007). Luz et al. ${ }^{12}$ (2007) found that most articles were published by the states of Rio de Janeiro, São Paulo, Minas Gerais, Rio Grande do Sul and Pernambuco.

This difference in the number of publications from the Brazilian states is due to the disparity between these states concerning the number of graduate programs and master's and doctorate vacancies, and also to the amount of resources allocated to the several support agencies for scientific research and initiation. The State of São Paulo ranks first in resources allocated ( $\mathrm{R} \$ 353.9$ million), whereas the State of Rio Grande do Sul is expected to be granted $\mathrm{R} \$ 11.25$ million for project development. ${ }^{21}$

The present study showed the trends in research on pediatric dentistry in Brazil and draws a picture of the knowledge produced. Thus, some areas of interest where little research has been done were identified, indicating that more research is needed on these topics. Also, it has become clear that scientific studies are not being conducted under very strict conditions and should be improved to ensure that the knowledge produced on dentistry be based on evidence.

\section{Conclusion}

It was concluded that most articles refer to studies with low potential to establish scientific evidence, indicating a need for conducting dental research based on better quality methodology.

Moreover, it was found that the assessed literature reflected the trends observed in the clinical practice of Pediatric Dentistry in Brazil. It further identified areas of interest where little research has 
been done, indicating a need for more research on these topics.

Furthermore, the present study indentified a disparity between the Brazilian states concerning proj-

\section{References}

1. Olsen NH. Recent and current research in pedodontics. J Am Dent Assoc. 1959 May;58(5):33-6.

2. American Academy of Pediatric Dentistry. Definition of pediatric dentistry. Pediatr Dent. 1999;21(5):4.

3. Loevy HT, Goldberg AF. Dominant research interests of pediatric dentists: dental materials, craniofacial biology and cariology. Pediatr Dent. 1995 Sep-Oct; 17(5):375-6.

4. Forrest JL, Miller AS. Enhancing your practice through evidence-based decision making. J Evid Base Dent Pract. 2001; $1(1): 51-7$.

5. Haynes RB, Sackett DL, Guyatt GH, Tugwell P. Clinical epidemiology: how to do clinical practice research. Philadelphia: Lippincott Williams \& Wilkins, 2006.

6. Mckibbon KA, Wilczynski N, Hayward RS, Walker-Dilks CJ, Haynes RB. The medical literature as a resource for health care practice. J Am Soc Inf Sci. 1995 Dec;46(10):737-42.

7. Kim MY, Lin J, White R, Niederman R. Benchmarking the endodontic literature on MEDLINE. J Endod. $2001 \mathrm{Jul}$; $27(7): 470-3$.

8. Okubo Y. Bibliometric Indicators and analysis of research systems: methods and examples. Paris: OCDE/GD, 1997.

9. Pritchard A. Statistical bibliography or bibliometrics? J Doc. 1969 Dec;25(4):348-9.

10. Yang S, Needleman DMDH, Niederman DMDR. A bibliometric analysis of the pediatric dental literature in MEDLINE. Pediatr Dent. 2001 Sep-Oct;23(5):415-8.

11. Fabro AT, Yoo HHB, Queluz THAT. Perfil da atividade de pesquisa publicada nos anais dos congressos brasileiros de pneumologia e tisiologia nos últimos vinte anos. J Bras Pneumol. 2006 Jul-Aug; 32(4):309-15. ect development and scientific production, reflecting the lack of governmental incentive and support to scientific and technological advancement in Brazil.

12. Luz MP, Nascimento AL, Mendlowicz M, Appolinario JC, Figueira I. Jornal Brasileiro de Psiquiatria: um estudo bibliométrico dos artigos publicados de 1995 a 2004. J Bras Psiquiatr. 2007;5(1):29-32.

13. Oliveira GJ, Oliveira ES, Leles CR. Tipos de delineamento de pesquisa de estudos publicados em periódicos odontológicos brasileiros. Rev Odonto Ciência. 2007 Jan-Mar; 22(55);42-7.

14. Suehiro ACB, Cunha NB, Oliveira EZ, Pacanaro SV. Produção científica da Revista Psico-USF de 1996 a 2006. Psico USF. 2007 Jul-Dez;12(2):327-34.

15. Fletcher RH, Fletcher SW. Clinical Epidemiology: the essentials. Baltimore: Lippincott Williams \& Wilkins, 2005.

16. Nainar SMH. Profile of pediatric dental literature: Thirty-year time trends (1969-1998). ASDC J Dent Child. 2001;68(56):388-90, 303.

17. Nainar SMH. Profile of Journal of Dentistry for Children and Pediatric Dentistry Journal articles by evidence typology: Thirty-year time trends (1969-1998) and implications. Pediatr Dent. 2000 Nov-Dec;22(6):475-8.

18. Susin C, Rösing CK. Praticando odontologia baseada em evidência. Canoas: ULBRA, 1999.

19. Haddad AE. Brazilian Oral Research: combining scientific excellence and social impact. Braz Oral Res. 2008 Jul-Sep; 22(3):195-6.

20. Cavalcanti AL, Melo TRNB, Barroso KMA, Souza FEC, Maia AMA, Silva ALO. Perfil da pesquisa científica em odontologia realizada no Brasil. Pesq Bras Odontoped Clin Integr. 2004 May-Aug; 4(2):99-104.

21. Cardoso D. A ciência gaúcha está de bolso vazio. Zero Hora. 2008 Out 22;28. 